\title{
Risk Management Tactics during the Globalization of the Enterprise
}

\author{
Zhihong Li' ${ }^{1}$, Dingbang $\mathbf{W u}^{2}$ \\ ${ }^{1}$ Business School, Jianghan University, Wuhan, China \\ ${ }^{2}$ Human Resources Department, Da Jia Insurance Company, Wuhan, China \\ Email: linanwudingbang@163.com
}

How to cite this paper: $\mathrm{Li}, \mathrm{Z}$. H., \& Wu, D. B. (2021). Risk Management Tactics during the Globalization of the Enterprise. Open Journal of Social Sciences, 9, 563-571. https://doi.org/10.4236/jss.2021.99041

Received: April 12, 2021

Accepted: September 26, 2021

Published: September 29, 2021

\begin{abstract}
The globalization is the needed path of the enterprise when its business has been developed to a certain stage since the global market connects more and more closely. Because of the influence from the politics, competition and culture, etc., the enterprise is bound to meet with multiple uncertainties or dangers. How does the enterprise cope with these risks? The enterprise must respond to this question beforehand. Therefore, the paper first exposes the current situations of the globalization and its functions to the business, next analyzes the evolution trend of the enterprise, then discusses some approaches to identify the risks during the business globalization, finally puts forward some tactics to deal with the risks for the enterprise to do the transnational business.
\end{abstract}

\section{Keywords}

Risk Management, Globalization, Transnational enterprise, Tactics

\section{Introduction}

In this multi-lateralized world, it is an inevitable trend for the enterprise to go overseas when it has been developed to a matured stage both in the aspect of the product and the management. However, due to the difference either in the political \& legal institutions, customs \& habits and culture, etc., the enterprise is obliged to face large quantities of the potential dangers or uncertainties when it runs its business abroad. If these risks can't be eliminated in time, they will gravely affect the production \& operation of the transnational enterprise. Sometimes, they may make it bankruptcy. Therefore, the enterprise must well be prepared in all directions of risk identification, risk management and risk removal tools and so forth in front of the risks. 


\section{Globalization Trend to Develop the Enterprise}

\subsection{About Globalization}

Globalization is a very important stage of the human society from the low level to high level. It concerns all walks of life such as politics, economy, education and culture, etc. As the internet is widely popularized and the science \& technology are fast developed, the globalization has been bringing various nations or regions and people together more and more closely and interdependently. When the globalization gives people or various nations opportunities to move forward, some issues like global governance, fair income distribution, cultural melting and multilateralism \& unilateralism (Yao, 2018), etc. These issues must be considered by the enterprise when it expands its market globally. As for the enterprise, the direct influence of the globalization lies in the following aspects:

First, the globalization makes the enterprise able to do business internationally. This is helpful for the enterprise to make a full use of the global resources and rationally arrange its production and operation (Pan, 2018). It can set up the factory in the nation or region which has a relatively low cost either in the human forces or in the natural resources and so forth. With the current advanced communication, transportation and payment system, the enterprise is able to select the productive materials with more competitive advantages during its global purchase. This can greatly cut down the purchase cost of the materials.

Then, the globalization provides some chances to select the needed skilled personnel in the whole world for the enterprise. The skilled personnel coming from different nations or regions can consolidate the melting of the resources in the enterprise and generate new ideas, which is able to raise its level of adapting to the different market demand. At the same time, the globalization does benefits to the enterprise to select the excellent people as quickly as possible and this greatly shortens the time to arrange the suitable person to the right position. After all, according to the usual laws to train the people, it takes one hundred years to cultivate people while it needs ten years to grow the tree.

However, in the course of the globalization, the enterprise still faces some challenges. The globalization often means the circulation of various resources and this will increase the uncertainties of doing businesses in the outer conditions. These uncertainties undoubtedly enlarge the difficulties of the enterprise to produce and operate, because in the global market, the customer's demand is much more diversified and fluctuating than that in the domestic market. The enterprise is obliged to innovate its items to meet the changing needs of the international consumer. In the meanwhile, the melting of the labor forces makes it much harder to effectively administrate the people from various nations or regions, for they have different backgrounds either in the education or in the culture or in the value perspectives or else. Moreover, during the globalization, the enterprise has to deal with the problems caused by the trade protectionism or unilateralism or politicization or ideological prejudice, etc. All these problems are bound to deplete much energy of the administrator in the enterprise and af- 
fect its production and operation.

\subsection{The Inevitable Trend of the Enterprise Evolution: Globalization}

Quite different from the past, owing to the wide application of the new-generation information technology, the current globalization is expanding a vast market for the enterprise in a low cost and with a high efficiency. By way of optimizing the arrangement of the resources in the global scope, the enterprise can maximize its benefits. The new coronavirus 2019, particularly the prevalence of the trade protectionism, unilateralism and hegemony has gravely impinged upon the economy in the world and caused the interruption of the global industrial chain \& supply chain and stopped the personnel flow among various nations or regions, but the fast development of science \& technology in information, communication and transportation, etc. makes it more and more closely for the resources either in the people or in the funds or in the natural resources to circulate globally. It is the inevitable trend for the enterprise to purchase and do business in the whole world. Also, it conforms with the laws of the human society evolution for the enterprise to go toward the nations or regions with comparative advantages. This is fully proved by the enterprises of China to extend successfully overseas during the new coronavirus 2019 though they have had to do away with many obstacles.

\section{Risk Identification for the Enterprise in the Course of Its Globalization}

Since the globalization is obliged when the economic society has developed to a certain stage. For the purpose of not being knocked out from the market competition, the enterprise must be confident in the global development and strengthen its competency to keep a lookout against the risk (You, 2014). Seeing that the international risk is changing and complicated, it is quite necessary for the enterprise to formulate a comprehensive risk-avoiding system so as to identify in advance the possible danger to the business operation and then better manage it.

The risk identification refers to the forecast of the possible danger to the operation of the business that may lead to a failure of the business production \& operation in the course of the globalization because of all kinds of uncertainties which makes the actual benefits diverged from the expected ones of the enterprise. These uncertainties may be caused by the natural disaster like epidemic, earthquake,etc or by the human factors like politics, market or culture and so on. Commonly speaking, the risks can be classified into the following aspects.

\subsection{Market Risks during the Globalization of the Enterprise}

The market risk mainly comes from the various cultural difference and the international rivals (Xia \& He, 2020). First, the cultural difference leads to a result: people's consumption way of life, work habits and value perspectives are quite 
different and the product demand and the employment in the enterprise are obliged to be modified according to the diversified market requirements in the different nations or regions. Therefore, too many uncertainties caused by the changing market are bound to bring many risks to the enterprise. Although the transnational company has had sufficient capitals, advanced technologies and qualified skilled personnel, all these may not make it do the business successfully if it can't adjust its strategy at any time to cater for the fluctuating market conditions. In particulars, the religion in the cultural elements often causes a total failure once the business violates it in the aspects of the advertisement propaganda, communication style, etc.

\subsection{Political \& Legal Risks Caused by the Authorities of Some Nations}

The political risks usually occur in the regional turbulence and the governmental replacement, etc. The replacement or regroup of the political authorities often leads to the turbulence in the regional turbulence, religious disputes and so on. These uncertainties may gravely affect the business of the transnational enterprise because the policy and legal stipulations to the foreign investment might be changed by the new government. Some host governments may limit the production \& operation of the transnational business for the purpose of their own political interests or by way of various levies. Besides, some host countries may take the advantage of the policy such as trade protectionism, exchange rate and international balance of payments, etc to restrain the transnational business. What's worse, some of them may modify their laws \& stipulations so as to rob the most benefits of the transnational enterprise. Take it for example, in the energy industry, the governments of the United States have controlled $70 \%$ petroleum resources by using series of ways in the politics, economy and diplomacy, etc, even starting wars in Iran and Iraq in the guise of anti-terrorism.

\subsection{Financial Risks Coming from the Inside and Outside Factors of the Enterprise}

The financial risks are often caused by the two kinds of factors. One is the influence from the inside the enterprise like insufficient capitals, issues of the funds turnover and credit lowered, etc. (Xu \& Zhao, 2006). These kinds of the risks can be easily found, though. It's worse that some invisible financial risks can't be evidently spotted because they are originated from the non-financial indicators in the operation, customers and employees. They mainly consist of strategic targets, administrative re-engineering, business potentials; customers' satisfaction, market share; the quality in the offerings \& service; innovative capacity and product adaptation to the changing market and so forth. These non-financial indicators may do little harm when they happen singly. However, once they have been accumulated to a certain degree, their harm will be enlarged step by step. In the end, the risks brought by them will directly endanger the financial indicators and even more the correspondent dangers can't be eliminated in a short period. 
Seeing that these invisible financial risks are hard to be precisely measured, the transnational company must make some preparations beforehand by a systematic approach.

\subsection{Risks in the Human Resources and Technology}

The risks in the human resources mean that the labor forces often come from different nations or regions with various cultural backgrounds, knowledge foundations and personalities in the course of the globalization of the transnational company (Su, Ma, \& Deng, 2019). The diversification of the labor forces brings lots of difficulties to the human resources management. First, the local high level manager in the oversea subsidiary or branch may make the transnational company in danger if he or she doesn't run the business according to the strategic direction. The people dispatched oversea may have the disputes with the local manager if they can't agree with some operational decisions. At the same time, the diversified labor forces will force the everyday supervision and the performance assessment to face many challenges if these institutions are not comprehensive enough. Then, as the globalization becomes deeper and deeper, the flow rate of the people will be higher and higher. The moderate people's flow rate can do benefits to the business, but too high flow rate of the employee, especially the person in the core position, will endanger the enterprise. All these phenomena in the human resources will produce many risks to the business of the transnational company. Besides, the technology transfer in the transnational operation may meet with some dangers such as low returns with high technology, copy, etc owing to the lack of the effective precaution measures. Particularly, to these hi-tech enterprise, its core competitive forces rely on the technology \& skilled personnel and the risks in the human resources and technology are the vital elements to be considered.

\section{Risk Management Tactics for the Enterprise during Its Globalization}

The risk management means that the enterprise can precisely hold the various uncertainties during its global operation by way of identifying, forecasting, measuring and analyzing all kinds of potential dangers and also can adopt the correspondent approaches to minimize the concerned loss and to insure the safe production \& operation. It directly concerns the security of the assets and operational benefits of the trans-enterprise. Generally speaking, the methods to manage the transnational risk consist of the risk avoidance, risk control, risk sharing, risk insurance, etc. (Song, Zhu, \& Li, 2015). To effectively deal with the diversified risks in the course of the global business, the detailed tactics to manage the uncertainties can be shown as follows.

\subsection{Establishment of the Joint Venture with the Enterprise in the Host Country}

The joint venture is often considered as an effective way to cut down the uncer- 
tainties during the global production \& operation by sharing the ownership right, managerial right and professional technology. It does good to such aspects as tariffs, local preferential policy and so forth. At the same time, through the cooperation with the local enterprise, the transnational enterprise can avoid some risks coming from the governmental constraint policy like localization ratio, technological contribution and so on. These limits are usually imposed on the foreign sole proprietorship enterprise for the purpose of protecting the local industry. In China, the typical joint venture occurs in the automobile industry, for example, Volkswagen from German, Peugeot Citroen from France, Honda from Japan and General Motors from the United States, etc. The cooperative production \& operation with the local enterprise can help the transnational enterprise avoid the tariff barrier and also make the product enjoy the national treatment like the local item. Besides, the transnational enterprise can select the country or region with the comparative advantage either in the resources or in the natural conditions or in the geography environment, etc. In this way, the transnational business will be run at a low cost or with much convenience.

\subsection{Technological Transfer Based on the Life Cycle of the Product}

During the globalization of the business, the transnational enterprise ought to implement the technological transfer (Yan, 2013) on the base of the life cycle of the product. Generally, the life cycle of the product includes introduction, growth, mature and decline. In the introduction, the product is to be recognized by the market and its technology is still at the stage of test. At this time, it is unsuitable to implement the technological transfer, otherwise, the new technology may be disclosed. During the growth period, the new outcome is still to be further well established in the market and the new technology is not strong enough to be transferred to the outside, or it will meet with the danger to be leaked and the relative market may be lost. Then comes the mature period of the product, in which the technology has been grown up and the concerned product has occupied the market. It is not easy for the rival to copy the technology. At this time, the transnational enterprise may transfer its matured technology outside so as to obtain more returns to its technological development. Finally, in the decline period, the market starts to shrivel and the relative technology is gradually substituted by the new technology. It is high time for the enterprise to find a way for the out of date technology in the other country. Otherwise, with the market going down, the product says good bye to the consumer and the concerned technology has to be terminated. If the technology is transferred outside, the correspondent can find a new market and the life cycle of the technology can be prolonged and its returns will be further expanded.

\subsection{Implementation of Flexible Tools in the Human Resource Management in Light of the Diversified Culture}

In the transnational enterprise, the working forces come from various nations or regions. They have so many differences in the value perspective, the attitude to 
the work and life, belief and life habit and so on because of their different social cultural backgrounds, political and lawful regulations and educational experience. The manager in the human resources department of the transnational enterprise must adopt the elastic administrative policy so as to fully stimulate their enthusiasm and initiative to the work. Take the pay management system for example. The enterprise can design an overall compensation system that will better cater for managing the people with diversified cultural background. Such kind of compensation system has the characteristics of combining the short-period encouragement with the long-period encouragement, the individual interests with the enterprise strategic target, the material motivation with the spiritual encouragement, etc. It consists of both monetary returns and non-monetary returns. In the aspect of the monetary returns, the fixed pay, the welfare and assurance can assure can do many benefits to retain the skilled personnel. The variable pay like performance, bonus, stock shares and so forth will help the enterprise fully motivate the people's working zeal. Besides, the variable pay can be effectively given according to the requirements of different levels of the staff, for instance, the bonus may be more valid for the common employee or the workers while the stock share or dividend will have more attractiveness to the higher level of employees or managers. The non-monetary returns such as better working conditions, caring for the employee's family member, etc. will make the skilled personnel perceive the kindness and warm of the enterprise, which is helpful to keep and motivate the people. What's more important, the non-monetary returns can be designed flexibly to the diversified demands of the people. These flexible approaches in the human resources management are bounds to promote the transnational enterprise to go far forward.

During the human resources management of the transnational enterprise, the internationalized skilled personnel team construction is quite obliged and important. The internationalized skilled personnel team consists of the people from the parent corporation, from the local people in the host country or from the other nations or regions. Particularly, the skilled personnel from the local people will help the enterprise better understand the local market environment or cultural backgrounds, then recognized as soon as possible by the local inhabitants. These can push the enterprise to melt into the local community and to sustain soon either in the production \& exploration or in the marketplace.

\subsection{Persistence in the Brand Innovation by Combining the Internationalization and Localization}

The continuous brand innovation according to the customer's demand of the local marketplace is the foundation for the transnational enterprise able to be sustainable development. Naturally, the brand innovation doesn't mean a total deny. It means that the transnational enterprise ought to maintain its good image of the existent brand on the one hand. On the other hand, it should make some reforms to its products based on the local customer's changing demands. In this way, the enterprise will be stabilized in the local marketplace and obtain 
the sustainable rival advantages. Also, it can give a good brand image among the local consumers. Usually, compared with the physical things, the brand image has stronger capacity to resist the risk. A good brand image will have a trans-cultural influence high above the commercial value.

\subsection{Consolidation of the Social Responsibility either to the Host Country or to the Mother Country or to the Others}

A good enterprise figure has much importance both in the domestic and overseas for the enterprise. It can be built up by way of carrying out the due social responsibility. First, the offerings from the transnational enterprise can't do harm to the people's health either in the mother country or in the host country or in the others. Then, the process of the production \& operation must be green and economic. That's to say, the production \& operation can't be done at the cost of sacrificing the natural environment and much consuming the resources or energy. The transnational enterprise ought to utilize the clean energy and recyclable resources for its processing through the industrial transformation \& upgrade in the aspect of technology \& process. Besides, the social public welfare undertaking is an important and effective path for the transnational enterprise to set up a good figure among the consumers. This kind of the social public welfare undertaking may be charitable donation, financial aid to the student or the hiring of the disabled person, etc. A good business figure is an important invisible assets. It will leave a deep and lasting impression on the consumer and have a long influence force in the market.

\section{Conclusion}

In the current complicated and changing international conditions, large quantities of unexpected risks \& dangers may occur at any times in the course of the globalization of the transnational enterprise. The enterprise is obliged to make enough preparations for dealing with these potential risk in the aspects of the business operation model, technological transfer, human resources management, brand innovation and enterprise image and so forth. Only by an overall risk warning and a comprehensive risk response plan can the transnational enterprise cope with the complicated market conditions in the globe.

\section{Acknowledgements}

The paper is funded by the Discipline Group of the Integrative Management between Economy and Industry in the City Circle, by the Wuhan Studies Institute, Hubei, China (IWHS20172001), and by Research Center on the Development of the Manufacturing Industry of the Wuhan City Circle, China (wz201607).

\section{Conflicts of Interest}

The authors declare no conflicts of interest regarding the publication of this paper. 


\section{References}

Pan, H. L. (2018). Economic Globalization Is the Best Way to Raise the Efficiency of the Resources Arrangement. https://www.sohu.com/a/276643551_614005

Song, B., Zhu, J. M., \& Li, X. (2015). Research of the Theory \& Method on the Financial Warning of the Business Based on the Big Data. Journal of the Central Financial \& Economic University.

Su, X. L., Ma, T., \& Deng, Y. L. (2019). Research of the Risk Identification \& Preventive Countermeasures during the International Operation of the National Enterprise. http://www.scicat.cn/7/guanlilunwen/20190925/2958055.html

Xia, H. S., \& He, T. T. (2020). Study on the Risk Identification Model in the Conditions of Globalization \& the Big Data. https://www.cnki.net

$\mathrm{Xu}, \mathrm{H} .$, \& Zhao, J. J. (2006). Study on the Risk Identification \& Preventive Management during the International Operation of the Medium-Small Firm in China.

Yan, X. (2013). Research of the Risk Prevention during the International Operation of the Hi-Tech Firm in China. Financial Field, No. 4, 88.

Yao, C. D. (2018). Main Features and Influence of the New Trade Protectionism.

You, Y. (2014). Research of the Risk Control Mechanism during the Internationalization of the Medium-Small Firm. 